\title{
Certification and coding of two underlying causes of death in the Netherlands and other countries of the European Community
}

\author{
JOHAN P MACKENBACH, ${ }^{1}$ WILLEM MJVAN DUYNE, ${ }^{2}$ AND MARCIA C KELSON ${ }^{3}$ * \\ From the Department of Public Health and Social Medicine, ${ }^{1}$ Erasmus University, Rotterdam, The Netherlands; \\ TNO Institute of Preventive Health Care, ${ }^{2}$ Leiden, The Netherlands; and the Institute of Education, ${ }^{3}$ University of \\ London, London, UK
}

SUMMARY Differences in certification and coding of causes of death between countries of the European Community were studied by sending sets of case histories to samples of certifying physicians. Completed certificates were coded by national coding offices and by a WHO reference centre. Detection fractions ranged from $60 \%$ to $92 \%$ in a first study (concerning cases of chronic obstructive pulmonary disease) and from $80 \%$ to $94 \%$ in a second study (concerning cases of cancer). A detailed analysis of the findings for the Netherlands, which performed very well in both studies, reveals a substantial frequency of errors in certification (as opposed to errors in diagnosis). Comparison of national and reference centre coding suggests that the Dutch coding process is to a certain extent adapted to the frequency of these certfication errors, leading to deviations from WHO coding rules. It is concluded that certification and coding practices should be studied together and that further international standardisation of coding practices will not necessarily improve the validity of national cause of death statistics.

The interpretation of mortality statistics by cause of death is usually complicated by uncertainties about possible biases arising from differences in certification and coding of causes of death. Data are reported from two studies which were attempts to obtain detailed information on certification and coding practices for a selection of causes of death in countries of the European Community. The method employed consisted of the distribution of sets of case histories to samples of doctors in the participating countries, who filled in death certificates for these cases. The certficates were subsequently coded by national coding offices and a World Health Organization (WHO) reference centre.

In order to understand what is being measured in this type of study it is necessary briefly to recall that the production of the numerical code representing the so-called "underlying cause of death" involves three steps: the diagnostic process; completion of a death certificate; and coding of the statements on the death certificate according to the rules and classifications provided by the International Classification of Diseases (ICD). ${ }^{1}$ In each of these steps, an error can take a patient with a (true) underlying cause of death $X$

Formerly in the Department of Community Medicine, United Medical and Dental Schools of Guy's and St Thomas's Hospitals, London, UK. to a code number representing another cause of death. Conversely, patients with other (true) underlying causes of death can erroneously receive the code number for $X$. This is illustrated in table 1 .

The schematic representation in table 1 suggests two simple measures for the validity of an observed number of deaths from cause $X$ :

- the "detection fraction": the proportion of deaths with a true underlying cause of death $X$ which actually receives the code number for $\mathbf{X}$;

-the "confirmation fraction": the proportion of

Table 1 Schematic representation of possible relations between "true" underlying causes of death and observed underlying cause of death codes

\begin{tabular}{llll}
\hline & \multicolumn{2}{l}{ Underlying cause of death code } \\
\cline { 3 - 4 } & & Diagnosis $X$ & All other \\
\hline True underlying & Diagnosis X & a & b \\
cause of death & All other & c & d \\
\hline
\end{tabular}

Detection fraction $=\frac{a}{a+b}$

Confirmation fraction: $=\frac{a}{a+c}$ 
deaths receiving the code number of $X$ which actually died from $X$.

Although both detection and confirmation fractions should ideally be $100 \%$, for epidemiological purposes it is generally sufficient that there are no important differences in detection and confirmation fractions between the "times, places, and persons" that are being compared. Studies in which sets of case histories are used are essentially an attempt to estimate (differences in) detection fractions in so far as these are determined by the second and third steps mentioned above (certification and coding, respectively).

Some of the results from the two European Community Studies on death certification and coding have already been published, ${ }^{2,3}$ concentrating on the overall pattern of differences. This pattern, which will be summarised briefly here, raised important questions on the exact nature and relative contribution of differences in certification and coding practices. A detailed analysis of the frequency of specific errors in certification, and of the contribution of certification and coding differences, is presented for the Netherlands.

\section{Methods}

In both studies, of which the first was carried out in 1981 and the second in 1983/84, sets of 10 case histories were sent to (different) samples of doctors in the then eight member countries (excluding Luxembourg) of the European Community. In most countries, including the Netherlands, names of doctors were extracted from random samples of death certificates received by national coding offices in a given month. In France and Italy, many certificates were unsigned or names were illegible and untraceable from the central offices. In Italy, therefore, a random sample of certifying doctors was obtained from regional registry offices stratified by town size. In France, it was possible to obtain a list of doctors from a single region, to eliminate doctors unlikely to complete certificates, and to draw a random sample from the remainder. In Germany, data protection policies operate which prevent access to death certificates. German doctors were therefore selected from registers of practising physicians in the Berlin (West) region only. The German sample of the first study included general practitioners and internists but excluded physicians in hospitals; the sample of the second study consisted of hospital internists.

Although more case histories were sent out, it is with a limited number of mutually comparable case histories that this article is concerned (table 2). The other case histories were descriptions of a variety of other conditions, the results of which cannot easily be summarised. The six case histories selected from the
Table 2 Case histories used for further analysis

\begin{tabular}{|c|c|c|c|}
\hline \multirow{2}{*}{$\begin{array}{l}\text { Study } \\
\text { I }\end{array}$} & \multicolumn{2}{|c|}{ Case history } & \multirow{2}{*}{$\begin{array}{l}\text { Intended 3-digit } \\
\text { ICD-9 codes } \\
\text { One of: } 490-493,496\end{array}$} \\
\hline & 1 & $\begin{array}{l}\text { Chronic obstructive pulmonary disease, } \\
\text { dies during acute infection }\end{array}$ & \\
\hline & 2 & $\begin{array}{l}\text { Chronic obstructive pulmonary disease, } \\
\text { progressive dyspnoea }\end{array}$ & One of: $490-493,496$ \\
\hline & 3 & $\begin{array}{l}\text { Chronic obstructive pulmonary disease, } \\
\text { dies during pneumonia }\end{array}$ & One of: $490-493,496$ \\
\hline & 4 & $\begin{array}{l}\text { Chronic obstructive pulmonary disease, } \\
\text { dies during acute severe dyspnoea }\end{array}$ & One of: $490-493,496$ \\
\hline & 5 & $\begin{array}{l}\text { Chronic obstructive pulmonary disease, } \\
\text { progressive dyspnoea }\end{array}$ & One of: $490-493,496$ \\
\hline & 6 & $\begin{array}{l}\text { Chronic obstructive pulmonary disease, } \\
\text { cor pulmonale }\end{array}$ & One of: $490-493,496$ \\
\hline \multirow[t]{5}{*}{ II } & 1 & $\begin{array}{l}\text { Bladder cancer, } \\
\text { dies during pneumonia }\end{array}$ & 188 \\
\hline & 2 & $\begin{array}{l}\text { Stomach cancer, } \\
\text { dies during pneumonia }\end{array}$ & 151 \\
\hline & 3 & $\begin{array}{l}\text { Cancer of cervix uteri, } \\
\text { dies in cachexia }\end{array}$ & 180 \\
\hline & 4 & $\begin{array}{l}\text { Malignant melanoma, } \\
\text { dies during pneumonia, }\end{array}$ & 172 \\
\hline & 5 & $\begin{array}{l}\text { Pleural mesothelioma, } \\
\text { dies after pulmonary embolism }\end{array}$ & 163 \\
\hline
\end{tabular}

first study all concern a death from chronic obstructive pulmonary disease (COPD), treated here as one diagnostic entity, although the ICD distinguishes between chronic bronchitis, emphysema, and asthma. The five case histories selected from the second study all concern a death from a specific form of cancer. Numbers 1 to 4 were rather straightforward; number 5 required a choice between two causes of death (of which a specific form of cancer was the right one).

The type of information presented in these case histories was the diagnostic information that would normally be available to hospital doctors or general practitioners certifying the death of a patient in their practice. Each doctor was asked to complete a death certificate, as used in his/her own country, as if certifying an actual death. An incentive of (the equivalent of) $£ 20$ was offered.

Reasonable response rates were obtained (table 3). The objective was to obtain approximately 50 doctors in each country. Response percentages were between $60 \%$ and $92 \%$ in the first study (excluding West Germany) and between $56 \%$ and $86 \%$ in the second study. For the Netherlands, response percentages were $67 \%$ and $65 \%$, respectively.

Completed certificates were sent for coding at national (in some countries, regional) coding offices, which treated the certificates according to practices in force at the time of the study. Finally, English translations of all certificates were sent to a WHO reference centre (which happened to be the English Office of Population Censuses and Surveys (OPCS)) for coding according to uniform criteria. 
Table 3 Response percentages

\begin{tabular}{|c|c|c|c|c|c|c|c|c|c|c|}
\hline Study & & Denmark & W Germany & $\begin{array}{l}\text { England \& } \\
\text { Wales }\end{array}$ & Ireland & Netherlands & Belgium & France & Italy & All \\
\hline II & $\begin{array}{l}\text { Complete replies (n) } \\
\text { Response }(\%)\end{array}$ & $\begin{array}{l}50 \\
83\end{array}$ & $\begin{array}{l}39 \\
71\end{array}$ & $\begin{array}{l}50 \\
74\end{array}$ & $\begin{array}{l}63 \\
63\end{array}$ & $\begin{array}{l}51 \\
65\end{array}$ & $\begin{array}{l}50 \\
86\end{array}$ & $\begin{array}{l}53 \\
56\end{array}$ & $\begin{array}{l}50 \\
70\end{array}$ & $\begin{array}{r}406 \\
70\end{array}$ \\
\hline
\end{tabular}

\section{Results}

After certification and coding by national coding offices, on average $83 \%$ of all cases received a correct underlying cause of death code, in both the first and the second study (table 4). There were, however, important differences between countries. In the first study, the degree of variation between countries was larger than in the second study. Italy and Belgium had distinctly lower than average detection fractions in the first study. Reference centre coding improved the detection fractions of Belgium and, although to a lesser extent, Italy, which suggests that the differences are completely (Belgium) or partly (Italy) explained by differences in coding. Ireland had a lower than average detection fraction in the second study, which improved only slightly after reference centre coding.

An interesting finding in both the first and the second study was that reference centre coding reduced the detection fractions for Denmark, West Germany, the Netherlands, and France (table 4). This suggests that certification practices are less reliable than the resulting national codes suggest, and that strict adherence to the rules for selection of the underlying cause of death by the reference centre more clearly exposes the errors in certification.

In order to gain more insight into these overall results, we classified the Dutch certificates according to the most serious certification error occurring on it. The Dutch death certificate is a translation, with minor modifications, of the internationally agreed medical certificate of cause of death. ${ }^{1}$ Part I contains the sequence of events going back from the "direct cause of death" under la to the "underlying cause of death" under 1c. Part II should contain other conditions contributing to death which are not causally related to the underlying cause of death.

The types of error considered for counting were, in order of diminishing seriousness:

-a false diagnosis in part I of the certificateexamples of this were "lung fibrosis" instead of COPD and "lung cancer" instead of mesothelioma; -no diagnosis mentioned on the certificate, only signs and symptoms or complications - examples of this were "cor pulmonale" without mention of the underlying COPD, and "pneumonia" without mention of the underlying cancer;

- the correct diagnosis on the certificate but in part II, "not causally related"-a frequent example of this in the first study was "pneumonia" in part I and COPD in part II;

- the correct diagnosis in part I but in a wrong sequence, not corrected by stating the interval between onset and death-an example of this was "cancer of the cervix" "due to cachexia".

While the first of these four types of error is clearly an error of diagnosis, the other three will more often be errors of certification (arising when the death certificate is being completed).

In both studies, about $20 \%$ of Dutch certificates showed one of these errors (tables 5 and 6 ). In the first study (table 5), "a false diagnosis in part I" was more

Table 4 Estimates of detection fractions $(\times 100 \%)$ for chronic obstructive pulmonary disease and a group of five specific cancers

\begin{tabular}{|c|c|c|c|c|c|c|c|c|c|c|}
\hline Study & & Denmark & W Germany & $\begin{array}{l}\text { England \& } \\
\text { Wales }\end{array}$ & Ireland & Netherlands & Belgium & France & Italy & All \\
\hline I & $\begin{array}{l}\text { COPD } \\
\text { (idem, after } \\
\text { reference centre coding }\end{array}$ & $\begin{array}{l}90 \\
(85)\end{array}$ & $\begin{array}{l}90 \\
(88)\end{array}$ & $\begin{array}{r}86 \\
(86)\end{array}$ & $\begin{array}{l}92 \\
(91)\end{array}$ & $\begin{array}{l}91 \\
(84)\end{array}$ & $\begin{array}{r}72 \\
(85)\end{array}$ & $\begin{array}{r}85 \\
(69)\end{array}$ & $\begin{array}{r}60 \\
(63)\end{array}$ & $\begin{array}{r}83 \\
(82)\end{array}$ \\
\hline II & $\begin{array}{l}5 \text { cancers } \\
\text { (idem, after } \\
\text { reference centre coding }\end{array}$ & $\begin{array}{l}85 \\
(76)\end{array}$ & $\begin{array}{l}90 \\
(83)\end{array}$ & $\begin{array}{r}80 \\
(79)\end{array}$ & $\begin{array}{r}74 \\
(79)\end{array}$ & $\begin{array}{l}94 \\
(85)\end{array}$ & $\begin{array}{r}83 \\
(84)\end{array}$ & $\begin{array}{l}84 \\
(78)\end{array}$ & $\begin{array}{r}82 \\
(87)\end{array}$ & $\begin{array}{r}83 \\
(81)\end{array}$ \\
\hline
\end{tabular}

Note: For definition of detection fractions see table 1; for codes used in determining detection fractions see table 2.

Some of the material on which the table is based has been published in another form by Kelson and Heller ${ }^{2}$ and Kelson and Farebrother. 
Table 5 Errors on death certificates, the Netherlands, first study (six cases of COPD)

\begin{tabular}{|c|c|c|c|c|}
\hline \multirow[t]{3}{*}{$\begin{array}{l}\text { Type of error (according to } \\
\text { doctor's entry) }\end{array}$} & \multicolumn{2}{|c|}{ All certificates } & \multicolumn{2}{|c|}{$\begin{array}{l}\text { Certificates receiving } \\
\text { "intended" code from }\end{array}$} \\
\hline & & & $\begin{array}{l}\text { National } \\
\text { coding } \\
\text { office }\end{array}$ & $\begin{array}{l}\text { Reference } \\
\text { centre }\end{array}$ \\
\hline & $n$ & $\%$ & $n$ & $n$ \\
\hline \multirow{2}{*}{$\begin{array}{l}\text { False diagnosis in part I } \\
\text { Only symptoms, complications, etc, } \\
\text { in parts I and II }\end{array}$} & 21 & 7 & 7 & 3 \\
\hline & 13 & 5 & 6 & 1 \\
\hline \multirow{2}{*}{$\begin{array}{l}\text { Correct diagnosis in part Il } \\
\text { Correct diagnosis in Part I } \\
\text { in false sequence* }\end{array}$} & 13 & 5 & 12 & 4 \\
\hline & 12 & 4 & 12 & 11 \\
\hline $\begin{array}{l}\text { No error: correct diagnosis in } \\
\text { part } I \text {, correct sequence }\end{array}$ & 228 & 79 & 225 & 221 \\
\hline Total number of certificates & 287 & 100 & 225 & 221 \\
\hline
\end{tabular}

Note: For "intended" codes, see table 2.

- Not corrected by stating the interval between onset and death

+ One certificate was returned not completed

Table 6 Errors on death certificates, the Netherlands, second study (five different cases of cancer)

\begin{tabular}{|c|c|c|c|c|}
\hline \multirow[t]{3}{*}{$\begin{array}{l}\text { Type of error (according to } \\
\text { doctor's entry) }\end{array}$} & \multicolumn{2}{|c|}{ All certificates } & \multicolumn{2}{|c|}{$\begin{array}{l}\text { Certificates receiving } \\
\text { "intended" code from: }\end{array}$} \\
\hline & & & $\begin{array}{l}\text { National } \\
\text { coding } \\
\text { office }\end{array}$ & $\begin{array}{l}\text { Reference } \\
\text { centre }\end{array}$ \\
\hline & $n$ & $\%$ & $n$ & $n$ \\
\hline \multirow{2}{*}{$\begin{array}{l}\text { False diagnosis in part I } \\
\text { Only symptoms, complications, etc, } \\
\text { in parts I and II }\end{array}$} & 3 & 1 & 1 & 0 \\
\hline & 3 & 1 & 0 & 0 \\
\hline \multirow{2}{*}{$\begin{array}{l}\text { Correct diagnosis in part II } \\
\text { Correct diagnosis in Part I } \\
\text { in false sequence* }\end{array}$} & 37 & 14 & 27 & 26 \\
\hline & 9 & 4 & 9 & 7 \\
\hline $\begin{array}{l}\text { No error: correct diagnosis in } \\
\text { part I, correct sequence }\end{array}$ & 203 & 80 & 202 & 183 \\
\hline All certificates & 255 & 100 & 239 & 216 \\
\hline
\end{tabular}

Note: For "intended" codes, see table 2.

* Not corrected by stating the interval between onset and death

frequent than each of the errors of certification sensu stricto, but added together these were present on not less that $14 \%$ of the certificates. Remarkably, many certificates, although in error received an "intended" (ie, corresponding to the case histories) underlying cause of death code from the national coding office. Part of this "correction" resulted from application of WHO coding rules, as is evident from the fact that reference centre coding also assigned an "intended" code to some of these certificates, especially in cases of a false sequence in Part I. Another part of this "correction", however, must be the result of strictly national coding practices. These coding practices apparently involve a lot of (re-)interpretation of the statements on the death certificate.

In the second study (table 6), by far the most frequent type of error was "correct diagnosis in part II". This was about as often corrected by the national coding office as by the reference centre. Now some discrepancies occurred for certificates that had been placed (by us) in the category "no error". These discrepancies were largely due to the fact that certificates for case history no 5 , stating "malignant mesothelioma" without mention of the site, were coded by the reference centre as "malignant neoplasm, site unspecified" and by the Dutch coding office as "malignant neoplasm of the pleura". This again is evidence of the interpretative efforts of the Dutch coding office.

\section{Discussion}

A recent bibliography of cause of death validation studies published between 1958 and $1980^{4}$ reveals that the use of sets of case histories to study differences in certification practices is relatively infrequent. Only one study employing this method was published during this period, ${ }^{5}$ investigating differences in certification of certain causes of death between the United States, the United Kingdom, and Norway. Another study from the same period examined international differences in coding by supplying sets of completed certificates to national coding offices. ${ }^{6}$ In 1982 , a study employing case histories appeared in this journal $^{7}$, which investigated regional differences in certification practices within England and Wales.

The studies reported here were unique in that certification and coding practices were investigated at the same time. The studies mentioned above examined either differences in certification between countries ${ }^{5}$ or differences in coding. ${ }^{6}$

It is evident from our studies that certification and coding practices should preferably be examined in combination. Some differences in certification will be compensated for in the process of coding. The fairly high Dutch detection fractions found for two (groups of) underlying causes of death result from reasonable performance in certification and a coding process adapted to the frequency of some certification errors.

Nevertheless, the overall results, after national coding, suggest that differences in certification and coding could in some cases be an important determinant of international mortality differences by cause of death. 
The main limitation of case history studies is that it is very difficult to ensure external validity. Neither choice and content of the case histories nor respondents' behaviour are necessarily representative of "real life". Nevertheless, the studies reported here have indirectly demonstrated a certain degree of external validity. Some of the discrepancies between countries found in the first study have been shown to correspond to observed mortality patterns, ${ }^{2}$ and the discrepancies found with the case history of cancer of the cervix in the second study have been shown to correspond to some observed mortality differences for this condition. ${ }^{3}$

The frequency of certain certification errors found in our detailed analysis of the Dutch material could give some clues for improvement.

The frequency of a correct diagnosis in part II of the certificate instead of in part I suggests that some doctors in the Netherlands do not quite understand the meaning of the phrase "other significant conditions contributing to the death, but not related to the disease or condition causing it" (which has a rather tortuous Dutch translation). It seems necessary to clarify the objectives of this part of the certificate.

In the meantime, further international standardisation of coding practices would not necessarily improve the validity of Dutch cause of death statistics.

We thank the participating doctors and the national coding offices for their cooperation. We are especially grateful to Mrs Dr LM Friden-Kill, medical officer of the Department of Death Statistics of the Dutch Central Bureau of Statistics, for invaluable contributions.

The work reported in this article is based on two studies supported by a grant from the Directorate
General for Employment and Social Affairs of the European Communities.

Members of the working party: Belgium: $M$ Kornitzer, YC Yernault; Denmark: J Mosbech, J Mosbech; France: R Pariente, F Neukirch; Germany: D Borgers, H Huckauf; Ireland: G Dean, E Shelley; Italy: A Marinoni, G Casali, M Grassi; Netherlands: JP Mackenbach, WMJ van Duyne; United Kingdom: WW Holland, RF Heller, MC Kelson, M Farebrother, J Goldschmidt; Commission of European Communities: $M$ van der Venne.

Correspondence and reprint requests to JP Mackenbach, Department of Public Health and Social Medicine, Erasmus University Rotterdam, PO Box 1738, 3000 DR Rotterdam.

\section{References}

${ }^{1}$ Anonymous. Manual of the international statistical classification of diseases, injuries and causes of death, 9th revision. Geneva: World Health Organization, 1977.

${ }^{2}$ Kelson MC, Heller RF. The effect of death certification and coding practices on observed differences in respiratory disease mortality in eight EEC countries. Rev Epidem et Santé Publ 1983; 31; 423-32.

${ }^{3} \mathrm{Kelson}$ MC, Farebrother M. The effect of inaccuracies in death certification and coding practices in the EEC on international cancer mortality statistics. Int $J$ Epidemiol 1987 in press.

${ }^{4}$ Gittelsohn AM, Royston PN. Annotated bibliography of cause-of-death validation studies: 1958-1980. Vital and Health Statistics, series 2, no. 89. Washington: US Government Printing Office, 1982.

${ }^{5}$ Reid DD, Rose GA. Assessing the comparability of death statistics (preliminary report). Br Med J 1964; 2: 1437-9.

${ }^{6}$ Anonymous. The accuracy and comparability of death statistics. WHO Chronicle 1967; 21: 11-7.

${ }^{7}$ Diehl AK, Gau DW. Death certification by British doctors: a demographic analysis. J Epidemiol Comm Health 1982; 36: 146-9. 